\title{
INFLUENCE OF PHYSICAL PROPERTIES OF WATER-ADJUVANT MIXTURE ON THE DROPLET STAINS DEPOSITING ON AN ARTIFICIAL TARGET
}

\author{
Marek MILANOWSKI ${ }^{1}$, Stanislaw PARAFINIUK ${ }^{\mathbf{1}}$, Anna KRAWCZUK ${ }^{\mathbf{1}}$, \\ Alaa SUBR ${ }^{2}$ \\ ${ }^{1}$ Department of Machinery Exploitation and Management of Production Processes, University of Life \\ Sciences in Lublin, POLAND \\ ${ }^{2}$ Department of Agricultural Machines and Equipment, College of Agriculture, University of Baghdad, \\ IRAQ \\ E-mail of corresponding author: marek.milanowski@up.lublin.pl
}

Keywords: adjuvant, stains, water sensitive papers, liquid temperature

\begin{abstract}
The study was designed to determine the effect of adding different concentration of the adjuvant $(0,50$ and $100 \%$ as compared to the recommended concentration from the adjuvant producer) on the surface tension of water from different sources and at different liquid temperature. As well as determining the stains spreading properties (area, diameter and coverage) on water-sensitive papers (WSP's) after the drops from different mixtures released from two heights. The volume of the released drops during the test of stains spreading was kept unchanged and irrespective of the surface tension obtained. The results show that adding the adjuvant produced a change in surface tension of the working liquid. As the adjuvant concentration increased, the surface tension decreased which in turn increased the spreading (area, diameter and coverage) of the stain on the WSP's especially at temperature of $10^{\circ} \mathrm{C}$.
\end{abstract}

\section{INTRODUCTION}

The spray application could be affected significantly by adding the adjuvant to the tank mixture; this influence depends on the properties of this adjuvant and its concentrations on the spray. This effect comes from the change in spray drops physicochemical properties (size, velocity, impact and spread behavior) as a result of adding the adjuvant (Holloway et al., 2000). Costa et al. (2017) reported decrease in the drops median diameter as a result of adding the adjuvant, this was accompanied by higher number of drops which tend to drift. This decrease was because of the surface tensions of those drops which decreased and it depended on the chemical group of the adjuvant. This decrease in the drop size as a result of reduction in the surface tension value was observed also by Basi et al. (2012), the measurement of the liquid was done by a spectrofluorophotometer and it was at lower impulse widths and larger orifice diameters of a pneumatic drop-on-demand generator system. Decaro Junior et al. (2015) found that the surface tension of a mixture of spraying liquid decreased when adding and when increasing the concentration of mineral oil (Argenfrut ${ }^{\circledR}$ ). Lin et al. (2016) found that adding the surfactant to deionised water and pesticide spray resulted in clear spreading of the drops on the leaf surfaces. In contrast, the drops of spray without the surfactant stayed in a spherical shape and did not spread. They found also that the best concentration of the surfactant was $0.25 \%$ to get better spreading of the drops and more wetted area. The same results were reported by Xu et al. (2010) in their study on waxy leaves, adding that this change depends on the plant species and the adjuvant class. They suggested that the proper choice of the adjuvant class enhanced the deposit formation on waxy leaves significantly which, in turn, will result in more effectiveness of pesticides. Xu et al. (2011) found that increasing the adjuvant concentration resulted in an increase in the wetted area on waxy and hairy leaf surfaces. They recommended using correct adjuvant concentration in the spray mixture which could lead to a great 
improvement on the spray coverage homogeneity on the target surfaces which, in turn, could reduce pesticide use.

The objectives of this work are:

1. Determine the effect of adjuvant concentrations and mixture temperature on the surface tension of water from different sources;

2. Determine the difference in the stains size and the stains coverage percentage on WSP depending on the drops releasing height for the individual adjuvant concentrations and temperature.

\section{METHODS}

The experiment tests were done in the pesticide application laboratory of the Department of Machinery Exploitation and Management of Production Processes University of Life Sciences in Lublin, Poland. Water sensitive papers (dimension: $26 \times$ $76 \mathrm{~mm}$ ) were used as an artificial surface for the deposited drops which were released from a needle (size $0.513 \mathrm{~mm}$ ) at two heights, with fixed drop volume equal to $14 \mu 1$. The treatments included the following parameters:

1. Adjuvant concentration: $0 \%, 50 \%, 100 \%$ of the manufacturer's recommended dose (50 $\mathrm{ml}$ for 1001 water)

2. Diluting water type (Table 1) : Distilled water (D); Water from the building of University of Life Sciences in Lublin (UP); Tap water from a farm located in the municipality of Sosnówka (S)

3. Liquid temperature: $10^{\circ} \mathrm{C} ; 15^{\circ} \mathrm{C} ; 20^{\circ} \mathrm{C}$

4. Releasing (of drops) height: $12.5 \mathrm{~cm} ; 25.0 \mathrm{~cm}$ (distance from needle tip to the WSP surface).

Table1. Density and hardness for the water types used in the tests

\begin{tabular}{|c|c|c|c|c|}
\hline \multirow{3}{*}{ Water type } & \multicolumn{3}{|c|}{ Density, $\mathrm{g} / \mathrm{cm}^{3}$} & \multirow{2}{*}{ Water hardness } \\
\cline { 2 - 4 } & 10 & 15 & 20 & \\
\cline { 2 - 4 } & 0.9997 & 0.9991 & 0.9982 & very soft \\
\hline D & 0.9998 & 0.9992 & 0.9983 & slightly hard \\
\hline S & 1.0001 & 0.9995 & 0.9986 & very hard \\
\hline UP & &
\end{tabular}

Five drops were released on each WSP, they were distributed randomly on the surface of WSP without touching one another (Figure 1). The WSP's were scanned after they were dried with a proper photos-resolution for the further investigation. The image pro software was used to analysis the WSP's photos and the following traits were calculated:

1. Stain area (in $\mathrm{mm}^{2}$ ); 2. Stains diameter (in $\mathrm{mm}$ ); 3. Stains percentage coverage (in \%)

Surface tension for the treatments liquid was measured using DSA30 KRÜSS GmbH Drop Shape Analyzer device and according to the pendant drop method. The type of adjuvant used in the test was SUPERAM 10AL (PZH-2825/2013 approval), it is moistens and enhances adhesion of the liquid mixture beside it has combined use with plant protection chemicals in field crops. 


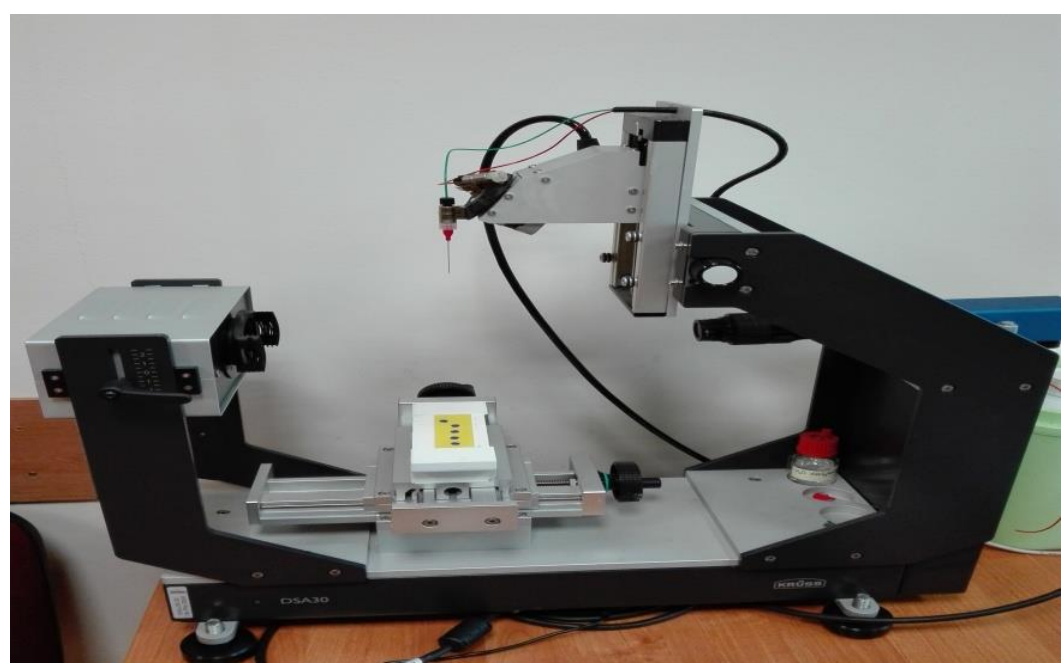

Figure1. Releasing the drops on the WSP's from the needle of DSA30 KRÜSS GmbH Drop Shape Analyzer device

\section{RESULTS}

The area for the released drops after they deposited on the surface of WSP had the highest value (Table 2) when using water type UP at temperature of $10^{\circ} \mathrm{C}$, also when using $100 \%$ concentration of the adjuvant and $25 \mathrm{~cm}$ releasing height.

Table2. Mean values for the area (in square millimeter) of deposited drops from different types of water, temperature, releasing heights, when adding different concentration percentage of adjuvant

\begin{tabular}{|c|c|c|c|c|c|c|c|}
\hline \multirow{2}{*}{ Adjuvant percentage, \% } & \multirow{2}{*}{ Water type* } & \multicolumn{3}{|c|}{ Height $12.5 \mathrm{~cm}$} & \multicolumn{4}{c|}{ Height $25.0 \mathrm{~cm}$} \\
\cline { 3 - 8 } & & \multicolumn{2}{|c|}{ Temperature, ${ }^{\circ} \mathrm{C}$} & \multicolumn{3}{|c|}{ Temperature, ${ }^{\circ} \mathrm{C}$} \\
\cline { 2 - 8 } & & 10 & 15 & 20 & 10 & 15 & 20 \\
\hline \multirow{3}{*}{0} & $\mathrm{D}$ & 31.1 & 29.8 & 28.1 & 34.5 & 33.3 & 33.2 \\
\cline { 2 - 8 } & $\mathrm{S}$ & 33.1 & 31.9 & 32.7 & 36.1 & 38.8 & 37.9 \\
\cline { 2 - 8 } & $\mathrm{UP}$ & 33.4 & 31.3 & 32.8 & 36.1 & 34.7 & 36.4 \\
\hline \multirow{3}{*}{50} & $\mathrm{D}$ & 31.3 & 24.3 & 24.8 & 35.2 & 27.8 & 27.0 \\
\cline { 2 - 8 } & $\mathrm{S}$ & 30.2 & 32.7 & 33.5 & 35.7 & 35.7 & 36.3 \\
\hline \multirow{3}{*}{100} & $\mathrm{UP}$ & 34.4 & 32.1 & 33.4 & 40.0 & 37.3 & 36.9 \\
\hline & $\mathrm{D}$ & 32.9 & 28.8 & 27.7 & 37.6 & 33.2 & 26.5 \\
\hline & $\mathrm{S}$ & 35.6 & 30.7 & 28.6 & 40.4 & 35.6 & 35.1 \\
\hline
\end{tabular}

* D-Distilled water; UP- tap water from the building of University of Life Sciences in Lublin; S- tap water from a farm located in the municipality of Sosnówka

Averaged diameter results for the deposited stain (Table 3) showed that releasing the drops from $25 \mathrm{~cm}$ height produced larger diameter stains comparing with $12.5 \mathrm{~cm}$ height. The smallest stain diameter was obtained when releasing the drops of distilled water $+50 \%$ concentration adjuvant mixture from $12.5 \mathrm{~cm}$ height and at temperature of $15{ }^{\circ} \mathrm{C}$. 
Table3. Mean values for the stains diameter (in millimeter) using different types of water, temperature, dispersing heights, when adding different percentage of adjuvant

\begin{tabular}{|c|c|c|c|c|c|c|c|}
\hline \multirow{3}{*}{$\begin{array}{c}\text { Adjuvant percentage, } \\
\%\end{array}$} & \multirow{3}{*}{$\begin{array}{l}\text { Water } \\
\text { type }\end{array}$} & \multicolumn{3}{|c|}{ Height $12.5 \mathrm{~cm}$} & \multicolumn{3}{|c|}{ Height $25.0 \mathrm{~cm}$} \\
\hline & & \multicolumn{3}{|c|}{ Temperature, ${ }^{\circ} \mathrm{C}$} & \multicolumn{3}{|c|}{ Temperature, ${ }^{\circ} \mathrm{C}$} \\
\hline & & 10 & 15 & 20 & 10 & 15 & 20 \\
\hline \multirow{3}{*}{0} & $\mathrm{D}$ & 6.23 & 6.11 & 5.93 & 6.58 & 6.45 & 6.44 \\
\hline & $S$ & 6.44 & 6.33 & 6.40 & 6.73 & 6.98 & 6.89 \\
\hline & UP & 6.48 & 6.26 & 6.41 & 6.81 & 6.60 & 6.76 \\
\hline \multirow{3}{*}{50} & $\mathrm{D}$ & 6.26 & 5.52 & 5.57 & 6.63 & 5.90 & 5.82 \\
\hline & $S$ & 6.15 & 6.41 & 6.49 & 6.69 & 6.70 & 6.75 \\
\hline & UP & 6.57 & 6.34 & 6.48 & 7.09 & 6.85 & 6.81 \\
\hline \multirow{3}{*}{100} & $\mathrm{D}$ & 6.43 & 6.00 & 5.87 & 6.87 & 6.45 & 5.75 \\
\hline & $S$ & 6.68 & 6.21 & 5.98 & 7.12 & 6.68 & 6.64 \\
\hline & UP & 6.58 & 6.10 & 5.98 & 7.25 & 6.62 & 6.57 \\
\hline
\end{tabular}

Increasing the concentration of the adjuvant resulted in higher values for the percentage coverage, especially from $25 \mathrm{~cm}$ releasing height (Table 4). The highest value occurred when the temperature of the mixture (water from UP) was $10{ }^{\circ} \mathrm{C}$. Releasing the drops from $12.5 \mathrm{~cm}$ height for the distilled water (has temperature of $15{ }^{\circ} \mathrm{C}$ and 50 percent adjuvant concentration) resulted in the lowest value for the stains coverage percentage $(25.0 \%)$.

Table 4. Mean values for the stains percentage area or coverage $(\%) \pm$ standard deviation using different types of water, temperature, dispersing heights, when adding different percentage of adjuvant

\begin{tabular}{|c|c|c|c|c|c|c|c|}
\hline \multirow{2}{*}{$\begin{array}{c}\text { Adjuvant } \\
\text { percentage, }\end{array}$} & \multirow{2}{*}{$\begin{array}{c}\text { Water } \\
\text { type }\end{array}$} & \multicolumn{3}{|c|}{ Height $12.5 \mathrm{~cm}$} & \multicolumn{3}{c|}{ Height $25 \mathrm{~cm}$} \\
\cline { 3 - 8 } & & \multicolumn{3}{|c|}{ Temperature, ${ }^{\circ} \mathrm{C}$} & \multicolumn{3}{c|}{ Temperature, ${ }^{\circ} \mathrm{C}$} \\
\cline { 3 - 8 } & $\mathrm{D}$ & $31.8 \pm 1.6$ & $30.5 \pm 0.9$ & $28.8 \pm 1.5$ & $35.3 \pm 1.3$ & $34.1 \pm 0.9$ & $34.0 \pm 2.5$ \\
\cline { 2 - 8 } 0 & $\mathrm{~S}$ & $33.8 \pm 0.4$ & $32.7 \pm 1.3$ & $33.5 \pm 0.4$ & $36.9 \pm 1.3$ & $39.7 \pm 1.3$ & $38.8 \pm 0.7$ \\
\cline { 2 - 8 } & $\mathrm{UP}$ & $34.2 \pm 0.5$ & $32.0 \pm 0.9$ & $33.5 \pm 0.8$ & $37.8 \pm 0.7$ & $35.6 \pm 1$ & $37.3 \pm 0.7$ \\
\hline \multirow{3}{*}{50} & $\mathrm{D}$ & $32.2 \pm 0.8$ & $25.0 \pm 0.8$ & $25.4 \pm 1.3$ & $36.0 \pm 0.9$ & $28.5 \pm 0.7$ & $27.6 \pm 1.6$ \\
\cline { 2 - 8 } & $\mathrm{S}$ & $30.9 \pm 1.8$ & $33.5 \pm 1.1$ & $34.3 \pm 1.0$ & $36.5 \pm 1.4$ & $36.5 \pm 1.6$ & $37.2 \pm 1.1$ \\
\cline { 2 - 8 } & $\mathrm{UP}$ & $35.2 \pm 0.5$ & $32.8 \pm 1.1$ & $34.2 \pm 1.1$ & $40.9 \pm 1.2$ & $38.2 \pm 0.9$ & $37.8 \pm 0.7$ \\
\hline \multirow{3}{*}{100} & $\mathrm{D}$ & $33.7 \pm 0.8$ & $29.5 \pm 0.9$ & $28.3 \pm 0.6$ & $38.5 \pm 1.9$ & $34.0 \pm 0.6$ & $27.1 \pm 1.1$ \\
\cline { 2 - 8 } & $\mathrm{S}$ & $36.5 \pm 1.6$ & $31.5 \pm 0.3$ & $29.3 \pm 0.9$ & $41.5 \pm 1.6$ & $36.4 \pm 1.1$ & $35.9 \pm 0.6$ \\
\cline { 2 - 8 } & $\mathrm{UP}$ & $35.4 \pm 1.7$ & $30.4 \pm 0.3$ & $29.2 \pm 0.9$ & $42.9 \pm 1.2$ & $35.7 \pm 1.3$ & $35.2 \pm 0.8$ \\
\hline
\end{tabular}

Generally, adding the adjuvant with $100 \%$ concentration reduced the surface tension for the mixture to the lowest values comparing with $50 \%$ and $0 \%$. The lowest value for the surface tension happened when using Sosnówka farm water at temperature of $20{ }^{\circ} \mathrm{C}$ and with $50 \%$ adjuvant concentration. 
Table5. Average surface tension values $(\mathrm{mN} / \mathrm{m})$ with standard deviation $(\mathrm{SD})$ using different types of water, temperature, when adding different percentage of adjuvant

\begin{tabular}{|c|c|c|c|c|c|c|c|}
\hline \multirow{3}{*}{$\begin{array}{l}\text { Water } \\
\text { type }\end{array}$} & \multirow{3}{*}{$\begin{array}{c}\text { Adjuvant } \\
\text { percentage, } \\
\%\end{array}$} & \multicolumn{6}{|c|}{ Temperature, ${ }^{\circ} \mathrm{C}$} \\
\hline & & \multicolumn{2}{|c|}{10} & \multicolumn{2}{|c|}{15} & \multicolumn{2}{|l|}{20} \\
\hline & & $\begin{array}{l}\text { Surface } \\
\text { tension }\end{array}$ & SD & $\begin{array}{l}\text { Surface } \\
\text { tension }\end{array}$ & SD & Surface tension & SD \\
\hline \multirow{3}{*}{$\mathrm{D}$} & 0 & 73.51 & 2.15 & 74.67 & 1.63 & 72.56 & 0.97 \\
\hline & 50 & 43.83 & 1.41 & 42.11 & 1.1 & 37.39 & 2.37 \\
\hline & 100 & 40.02 & 1.48 & 38.47 & 1.32 & 35.84 & 1.12 \\
\hline \multirow{3}{*}{$\mathrm{S}$} & 0 & 75.56 & 1.2 & 72.73 & 1.34 & 72.25 & 1.27 \\
\hline & 50 & 45.87 & 1.73 & 44.7 & 1.64 & 33.22 & 1.6 \\
\hline & 100 & 39.16 & 2.2 & 36.46 & 1.37 & 35.92 & 3.23 \\
\hline \multirow{3}{*}{ UP } & 0 & 67.96 & 2.34 & 67.77 & 0.84 & 71.04 & 1.45 \\
\hline & 50 & 42.55 & 1.29 & 38.78 & 2.46 & 36.43 & 1.32 \\
\hline & 100 & 37.23 & 1.41 & 35.43 & 1.11 & 34.07 & 0.98 \\
\hline
\end{tabular}

From those results we can notice that using the laboratory tap water (UP water) with $100 \%$ concentration adjuvant and at $10{ }^{\circ} \mathrm{C}$ produced higher values for stains area, diameter and percentage coverage when the drops of this water released from $25 \mathrm{~cm}$ height. When linking these results with the surface tension measurement, we can conclude that to gain higher percentage coverage, the surface tension must be reduced to the possible lowest value. However, the water from Sosnówka farm, which has the lowest surface tension value, did not produced the highest coverage percentage and this is probably because of the physical properties of the water which are beyond the current study scope.

\section{CONCLUSIONS}

Adding the adjuvant especially with higher concentrations reduced the values of surface tension of the adjuvant-water mixture. This decrease in the surface tension produced higher values of stains area, diameter and percentage coverage especially at temperature of $10^{\circ} \mathrm{C}$.

\section{REFERENCES}

Basi, S., Hunsche, M., Damerow, L., Lammers, P. S., \& Noga, G. (2012). Evaluation of a pneumatic drop-on-demand generator for application of agrochemical solutions. Crop protection, 40, 121-125.

Costa, L. L., Silva, H. J., Almeida, D. P., Ferreira, M. D. C., \& Pontes, N. D. C. (2017). Droplet spectra and surface tension of spray solutions by biological insecticide and adjuvants. Engenharia Agrícola, $37(2), 292-301$.

Decaro Junior, S. T., Ferreira, M. D. C., \& Lasmar, O. (2015). Physical characteristics of oily spraying liquids and droplets formed on coffee leaves and glass surfaces. Engenharia Agrícola, 35(3), 588-600.

Holloway, P. J., Ellis, M. B., Webb, D. A., Western, N. M., Tuck, C. R., Hayes, A. L., \& Miller, P. C. H. (2000). Effects of some agricultural tank-mix adjuvants on the deposition efficiency of aqueous sprays on foliage. Crop Protection, 19(1), 27-37.

Lin, H., Zhou, H., Xu, L., Zhu, H., \& Huang, H. (2016). Effect of surfactant concentration on the spreading properties of pesticide droplets on Eucalyptus leaves. Biosystems Engineering, 143, 42-49.

Xu, L. Y., Zhu, H., Ozkan, H. E., Bagley, W. E., Derksen, R. C., \& Krause, C. R. (2010). Adjuvant effects on evaporation time and wetted area of droplets on waxy leaves. Transactions of the ASABE, 53(1), 13-20.

Xu, L., Zhu, H., Ozkan, H. E., Bagley, W. E., \& Krause, C. R. (2011). Droplet evaporation and spread on waxy and hairy leaves associated with type and concentration of adjuvants. Pest Management Science, 67(7), 842-851. 